\title{
Building and Perfecting the Service System of Entrepreneurship to Promote College Students' Entrepreneurship
}

\author{
Li Jingli ${ }^{1, a}$, Li Gang ${ }^{2, b, *}$ \\ ${ }^{1}$ School of Marxism, Baicheng Normal University, Jilin, Baicheng, 137000, China \\ ${ }^{2}$ School of Mechanical Engineering, Baicheng Normal University, Jilin, Baicheng, 137000, China \\ a337453323@qq.com, b20905612@qq.com \\ *corresponding author: LI Gang, 20905612@qq.com
}

Keywords: Entrepreneurship, Innovation, Service system, Employment.

\begin{abstract}
Under the current educational background of "mass entrepreneurship and mass innovation", some colleges and universities in China have accelerated the pace of transformation and development to meet the new needs of the development of higher education in the new era. However, the overall employment situation of college graduates is still not optimistic, and the employment and entrepreneurship of college students have increasingly attracted the attention of society and colleges. College students' entrepreneurship education in China is still in the exploratory stage. There are some problems, such as the imperfect service system for college students' entrepreneurship, the inadequate implementation of college students' entrepreneurship policy, the unreasonable curriculum system, the imperfect hatching supporting policies and service mechanisms. This paper analyzes the main reasons for the problems, and proposes that it is of farreaching practical significance to build and improve the service system of college students' entrepreneurship from three aspects: government, society and colleges.
\end{abstract}

\section{Introduction}

Today is the era of knowledge economy based on knowledge and innovation. in order to successfully promote the strategic adjustment of economic structure and realize the rapid transformation and coordinated development of economy, China must vigorously develop the knowledge economy, which requires perfecting the construction of a reasonable entrepreneurial service system, cultivating college students' entrepreneurial awareness and enhancing their entrepreneurial ability. This is positive to solve the problem of college students' employment difficulties and to improve the national scientific and technological strength, and it is also an inevitable requirement to effectively support and promote the development of college entrepreneurship education system in China.

\section{The significance of college students' entrepreneurship}

National leaders have repeatedly mentioned: "innovation is the soul of a nation and the inexhaustible motive force for the prosperity of a country." The younger generation, especially college students, is the most dynamic group in China. if we lose the motivation to create, but settle in the present situation or stick to the rules, then the Chinese nation will eventually lose the strength to develop forward. It is of great significance to promote college students' entrepreneurship and correctly guide their employment ${ }^{[1]}$.

\subsection{College students' entrepreneurship creates opportunities for them to improve themselves}

In the process of starting a business, we can apply the theoretical knowledge we have learned in practice, and at the same time improve our own creative consciousness and fighting spirit. we can learn from the failure and know which aspects of our knowledge are insufficient. We can make up for the lack of knowledge in class in a targeted way, and finally make preparations for becoming a 
comprehensive development-oriented talent.

\subsection{College students' entrepreneurship relieves the national employment pressure}

With the continuous enrollment expansion of colleges and universities in recent years, the number of graduates has reached a new high, the contradiction between social employment supply and demand is prominent, and the domestic employment situation is increasingly grim. College students' self-employment can not only solve their own employment problems, but also add new jobs to society by establishing companies, relieve the employment pressure of the country and make contributions to social stability.

\subsection{College students' entrepreneurship to create an entrepreneurial atmosphere in colleges and universities}

College students' entrepreneurship can improve the infectivity of campus culture. by initiating the brand of entrepreneurial culture, holding successful entrepreneurial exchange meetings and innovative entrepreneurial competitions and other activities, students' innovative enthusiasm is driven, an entrepreneurial culture is cultivated, students' entrepreneurial enthusiasm is stimulated, students' confidence in independent entrepreneurship is strengthened, the atmosphere of entrepreneurial culture on campus is better created, and contributions are made to promoting the reform of school education mode at the same time ${ }^{[2]}$.

\section{The current situation of entrepreneurial service system}

The service system of college students' entrepreneurship refers to the organic complex formed with the living environment of college students' entrepreneurial enterprises, which is composed of service items, service subjects, service mechanisms, service means and service performance, and is a relatively stable ecological mechanism to promote the sustainable development of college students' entrepreneurial enterprises, in order to improve the "survival rate" and "success rate" of college students' entrepreneurial enterprises ${ }^{[3]}$.

Service system is the most important external environment for the survival and development of college students' entrepreneurial enterprises, and it is the key factor to solve the problem of college students' entrepreneurship. Our investigation shows that college students are still facing the dilemma of "four shortages" at present. One is the lack of in-depth thinking. Some college students choose entrepreneurial projects with full of passion and self-feeling, and they lack in-depth thinking and market research, especially the way to achieve their goals. This requires the school to guide entrepreneurship correctly and guide them to make full preparations. Second, there is a lack of entrepreneurial skills. Lack of experience has brought different degrees of influence to their own development, which requires strengthening employment training and improving entrepreneurial skills. Third, there is a lack of start-up capital. At present, the venture capital of college students is mainly from team self-financing and bank lending besides some government subsidies. Because enterprises need a lot of money to maintain normal operation, workers' salaries and investment, and the channels of financing are limited, once they can't make profits as soon as possible, which leads to the breakage of capital chain, enterprises will face bankruptcy, which makes entrepreneurs heavily indebted and thus business failure. In order to avoid this phenomenon, we need to establish a sound venture capital financing service system. Fourth, there is a lack of effective policy support. Can't provide convenient conditions for entrepreneurs, escort the development of enterprises, and even some policy measures deviate from the expectations of enterprises in the implementation process, which requires us to establish a set of policy service system.

We believe that the existence of the above problems is caused by some college students' inadequate preparation for entrepreneurship and lack of related factors. On the other hand, it is caused by the lack of close links among all aspects of college students' entrepreneurial service system and the phenomenon of "chain breakage". Government departments pay more attention to the early support, pay insufficient attention to the whole ecological chain of college students' entrepreneurial enterprises and lack of comprehensive and sustainable strategic thinking. College 
students' entrepreneurship has not yet formed a service mechanism with effective operation and strong guarantee, so it is urgent to construct the service system of college students' entrepreneurship $^{[4]}$.

\section{Improve the construction of entrepreneurial service system to promote college students' entrepreneurship}

At present, the effectiveness of college students' entrepreneurship policy still needs to be further realized, and the construction of college students' entrepreneurship service system should pay attention to its integrity and strategy, and give full play to the linkage role of government, universities and society. To find ways and means to solve the problem and expand the employment of college students, we need the joint efforts of the government, society and universities to build and improve the existing service system of college students' entrepreneurship and employment ${ }^{[5]}$.

\subsection{Government: improving related policy system}

First, the government should improve the entrepreneurship policy system, which is the premise and guarantee of improving the local government's entrepreneurship service system. Second, the government should adhere to promoting social employment, further straighten out the employment system of college students, stick to market orientation, formulate preferential policies, attract and encourage college graduates to work in underdeveloped areas such as the grassroots and the west, and encourage graduates to work at the grassroots level by various means, such as subsidies for urban communities and rural grassroots jobs, compensation for student loans, taking postgraduate examinations and taking an examination of civil servants plus points, as well as expanding plans such as "three supports and one help", "northern Jiangsu volunteer service scheme" and "college village officials". Third, encourage self-employment. College graduates should not only be competitors of existing jobs in society, crowding out employment opportunities, but also be pioneers of new jobs, bringing employment opportunities to society. According to the survey data, the shortage of funds is still the main bottleneck restricting college students' entrepreneurship, and the government should introduce preferential policies to encourage all kinds of capital to invest in new high-tech entities of graduates. Set up college students' entrepreneurial base, and provide professional guidance, legal advice, market analysis and other services for entrepreneurial college students ${ }^{[6]}$.

\subsection{Society: concepts keep pace with the times}

It is imperative to change the social concept of college students' employment. we should thoroughly get rid of the traditional concepts of "five grades" and "nine grades" which are fixed in people's minds, and truly form the workers' awareness of no distinction between high and low. College graduates should adjust their employment expectations according to the supply and demand of talents in society. Can't be confined to work in economically developed areas and hot industries, but many areas and industries which are not favored by college students are in urgent need of talents $^{[7]}$.

\subsection{Colleges and Universities: there is no delay in the reform of Education}

1) The employment rate of graduates has become an important sign to measure the effectiveness of a university. Colleges and universities should constantly improve their educational level, change their training mode in a timely manner, follow up the trend of international education, and strengthen exchanges and cooperation in higher education. The education reform in Colleges and universities must be guided by the market, closely related to the actual situation of economic and social development, to speed up the adjustment of professional settings in Colleges and universities, to rationally allocate educational resources so as to cultivate the talents needed by the society. Professional setting, curriculum construction to meet the market requirements, according to different specialties scientifically enacted the number of enrolment, to improve the number of students in urgent need of professional enrollment, the quality of teaching is not high, professional 
settings are not reasonable to reduce the number of enrollment and even stop recruitment ${ }^{[8]}$.

2) Try to build a joint training mode between schools and enterprises and establish vocational training institutions. Combining the theoretical knowledge in class with the operation in practical work improves the operation skills and practical ability of college students. At the same time, the school should establish vocational training institutions, set up professional quality education and innovative entrepreneurship courses, combine professional quality training with practice, and truly solve the problem of decoupling between school education and market demand ${ }^{[9]}$.

3) Universities should strengthen the employment guidance work for university graduates. To meet the students' needs for life development and career design, throughout the university education, it not only makes up for the shortcomings of the previous employment guidance, but also enriches the ideological and political education system of college students. The theoretical research and practical operation of employment guidance should be strengthened to enable students to make full use of time resources for beneficial activities, thus reducing their chances of contact with bad information, which is more important today in the information society ${ }^{[10]}$.

\section{Conclusion}

The employment of college graduates is related to the economic construction, social stability and the fundamental interests of the people. It is related to the reform and development of the school. We must be aware of the seriousness of the employment of graduates in the current employment situation, and the employment of graduates is a long way to go. In order to promote the employment of graduates and build a socialist harmonious society, we must study deeply and be brave to practice and build the service system of graduates with Scientific Outlook on Development.

\section{Acknowledgements}

This work was partly supported by the Jilin Provincial Department of Education Humanities and Social Sciences Research Project (project Number: Ji Jiao Ke Wen He Zi [2016] No.15) and Jilin Provincial Department of Education vocational education and adult education reform research project in 2016 (project Number: 2016ZCY002).

\section{References}

[1] LI Ying. The Research of Local College Students Entrepreneurial Support System[D]. Wuhan Institute of Technology, 2017.

[2] ZHAO Yinghua, Lin Ling. The Construction of Guidance Service System for College Students[J]. Reform and Opening Up, 2016(13):109-111.

[3] ZHENG Guoliang. The Government Promotes the Development of College Students' Innovation and Entrepreneurship[J]. Knowledge Economy, 2018(8):133-134.

[4] HU Nannan. Research on College Students' Entrepreneurship Education Under the Background of Mass Entrepreneurship and Innovation[D]. Chongqing University of Technology, 2018.

[5] LI Shengli. Collaborative Entrepreneurship Service System for College Students[J]. Education and Occupation, 2017(24):70-72.

[6] JING Kunyu. Analysis on the Problems and Countermeasures of College Students Employment and Entrepreneurship Under the Background of Higher College Transformation[J]. Journal of HUBEI Correspondence University, 2018,31(9):1-3.

[7] LIU Xin, YU Mengmeng. Research on Establishing College Students' Innovative and Entrepreneurial Service System-Taking Shandong Jiaotong University as a Case Study[J]. JOURNAL OF GUANG DONG COMMUNICATION POLYTECHNIC, 2017,16(2):122-124.

[8] LI GANG, LI Jingli. The Exploration Study of the Application of Innovative Talents Training Mode in Colleges and Universities[J]. Journal of Baicheng Normal University, 2017(6):61-63.

[9] YAO Haowei, Chang Liang, Li Ling, et al. Research and Practice of "Four in One" College, Local, Teachers and Students' Innovation and Entrepreneurship Service System of College 
Students[J]. South Issue, 2018(2).

[10] YU Ende. Research on the Strategic System of Entrepreneurship and Employment for Newly Established Universities[J]. China Education Journal, 2015(S1). 